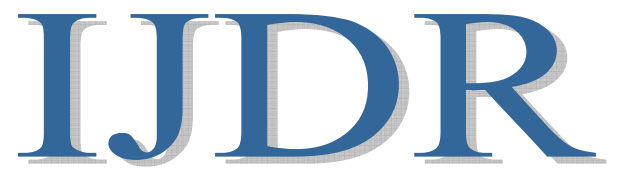

International Journal of Development Research

Vol. 10, Issue, 05, pp. 35903-35907, May, 2020

https://doi.org/10.37118/ijdr.18749.05.2020

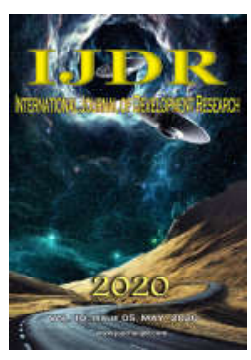

\title{
MAJOR APPROACHES THE ORBIT FRACTURE AND SURGICAL TREATMENTS: A SYSTEMATIC REVIEW
}

\section{Rogério Luiz de Araújo Vianªnd Idiberto José Zotarelli Filho ${ }^{*}$}

\author{
1Santa Casa Hospital-Bucomaxillo Facial Traumatology Center- Ribeirão Preto/SP, Brazil \\ 2Zotarelli-Filho Scientific Work of Sao Jose do Rio Preto/SP, Brazil
}

\section{ARTICLE INFO}

\section{Article History:}

Received $03^{\text {rd }}$ February, 2020

Received in revised form

$17^{\text {th }}$ March, 2020

Accepted $21^{\text {st }}$ April, 2020

Published online $30^{\text {th }}$ May, 2020

\section{Key Words:}

Fractures,

Orbit fracture,

Surgical treatments.

\begin{abstract}
Introduction: Fractures of orbital rupture are common. The same is true for surgical complications when the efficiency of dissection of the trapped intra-orbital content or hernia in the fracture could not be dissected completely and safely. In this sense, blow-out orbital fractures are those that affect exclusively the floor and/or the medial orbital wall. Orbital injuries are frequently seen in facial trauma and can cause a wide range of functional problems such as enophthalmos and diplopia, as well as aesthetic deformities. Objective: Conduct a systematic review of the main approaches to orbit fracture and surgical treatments in clinical studies. Methods: The present study followed a systematic review model. After literary search criteria using the MeSH Terms that were cited in the item below on "Search strategies", a total of 48 clinical studies were compared and submitted to the eligibility analysis, and, after that, 18 studies were selected, following the systematic review rules - PRISMA. Major findings and conclusion: Orbital injuries are frequently seen in facial trauma and can cause a wide range of functional problems such as enophthalmos and diplopia, as well as aesthetic deformities. The need for surgical treatment of these fractures is quite controversial. Some blow-out orbital fractures do not have sequelae if they are not surgically treated, while others can result in aesthetically unacceptable enophthalmos and/or disabling diplopia. The main issue, therefore, is the identification of those patients who require surgical intervention, the time of surgery, and the surgical technique involved.
\end{abstract}

*Corresponding author: Idiberto José Zotarelli Filho

Copyright (C) 2020, Rogério Luiz de Araújo Vian and Idiberto José Zotarelli Filho. This is an open access article distributed under the Creative Commons Attribution License, which permits unrestricted use, distribution, and reproduction in any medium, provided the original work is properly cited.

Citation: Rogério Luiz de Araújo Vian and Idiberto José Zotarelli Filho. "Major approaches the orbit fracture and surgical treatments: a systematic review", International Journal of Development Research, 10, (05), 35903-35907.

\section{INTRODUCTION}

According to WHO data, trauma is the main cause of death and disability in the world (Nazimi, 2019). Facial and head injuries reach half of the trauma deaths, and thousands are sequeled for long periods of time or permanently (Oliveira, 2008; Agudelo-Suárez, 2015). Such accidents affect people independent of socioeconomic status (Affonso, 2010). Facial fractures are considered a public health problem in several countries 4, such as the United States of America, which analyzed the occurrence of mandible fractures using the same parameters used in the present study (Afrooz, 2015), in Italy (Roccia, 2019), Germany (Schneider, 2010), India (Sameer Kaura, 2018) and studies in Brazil report various types of facial trauma and fractures (Bernardino, 2017; Paes et al., 2012) and its etiology is diverse mechanisms such as aggression or accidents that can affect people in any age group or social level (Jefferson, 2012; Affonso, 2010; Schneider, 2010).
There are articles that relate accidents with age and gender (Jefferson Viapiana Paes, 2012; Ailane Milard, 2019; Muñante-Cárdenas, 2011). In certain regions, there are variations regarding the trauma etiology. Some places have a higher incidence of traffic accidents (Scariot), others a higher incidence of aggression (Segundo avl, 2005; Caio de Andrade Hage, 2018), sports accidents: such as football (Brucoli et al., 2019), combat sports (Beaudouin, 2019) and, still, regions with high accident rates cycling affecting adults and children (Hojjat, 2016; Benjamin, 2018; Plawecki, 2017; Svider, 2016). In this context, orbital rupture fractures are common. The same is true for surgical complications when the efficiency of dissection of the trapped intra-orbital content or hernia in the fracture could not be dissected completely and safely. The literature describes a modification of the Howarth periosteal elevator commonly used for dissection of displacement of intra-orbital content or hernia in fracture of orbital rupture (Kang, 2019). 
The instrument was modified by marking the tip instrument at $10,20,25,30$ and $40 \mathrm{~mm}$ on both concave and convex surfaces to allow safe dissection of the orbital soft tissues and distance control. These simple modifications to the instrument's original design allow for better intraoperative control and appreciation of any important intact intraorbital anatomical structures, such as infer medial support and posterior border. While it is important to achieve complete dissection and visualization of the orbital fracture, it causes less trauma to the surrounding soft tissue with the markings, ensuring unnecessary exploration or visualization. The dissection can bemaintained for optimalmaneuverability at the required or desired location, based on the preoperative scan or the size of the anatomical orbital implant (Kang, 2019).

In this sense, blow-out orbital fractures are those that affect exclusively the floor and/or the medial orbital wall. The diagnosis of these fractures is based on physical examination and imaging tests (Rahbin, 2019). On physical examination, signs and symptoms, such as periorbital ecchymosis, limited eye movements, diplopia, and enophthalmia, may be present. Computed tomography is the most efficient test for diagnosing these fractures. Treatment must be carried out by reconstructing fractured orbital walls with autogenous, homogeneous, heterogeneous, or alloplastic materials. Thus, titanium screens proved to be efficient, showing good results in relation to the ability to reconstruct the orbital floor and to support the contents of the eyeball (Rahbin et al., 2019). Blowout orbital fractures were initially published by Smith and Regan in 1957. Currently, they are classified as pure blow-out fractures, which are isolated fractures of the orbital floor, and impure fractures, which are associated with fractures of the orbital floor. orbital arch, involving other facial bones. The theories most commonly accepted to explain the etiology of these fractures are the theory of hydraulic pressure inside the orbit and that of direct impact. Orbital injuries are frequently seen in facial trauma and can cause a wide range of functional problems such as exophthalmos and diplopia, as well as aesthetic deformities (Snäll, 2019).

The diagnosis of orbital fractures is made by the combination of clinical and imaging findings. The signs and symptoms most frequently associated with these fractures are periorbital and/or subconjunctival ecchymosis, enophthalmos, orbital pain, infra-orbital nerve paraesthesia, and diplopia (30). Conventional radiographic shots have little sensitivity and specificity in the diagnosis of these fractures. Computed tomography plays a fundamental role in the diagnosis and assessment of the extent of these fractures. The need for surgical treatment of these fractures is quite controversial. Some blow-out orbital fractures do not have sequelae if they are not surgically treated, while others can result in aesthetically unacceptable enophthalmos and/or disabling diplopia. The main issue, therefore, is the identification of those patients who require surgical intervention, the time of surgery, and the surgical technique involved (Snäll, 2019). Therefore, the present study aimed to conduct a systematic review of the main approaches to orbit fracture and surgical treatments in clinical studies.

\section{METHODS}

Study Model: The present study followed a systematic review model. After literary search criteria using the MeSH Terms that were cited in the item below on "Search strategies", a total of 58 clinical studies were compared and submitted to the eligibility analysis and, after that, 36 studies were selected, following the systematic review rules - PRISMA (Transparent reporting of systematic reviews and meta-analyzes-http: //www.prisma-statement.org/).

Search Strategy and Information Sources: The search strategy was carried out in the databases Pub Med, Embase, Ovid and Cochrane Library, Web Of Science, Science Direct Journals (Elsevier), Scopus (Elsevier), One File (Gale) followed the following steps: - search by MeSH Terms: Fractures. Orbit fracture. Surgical treatments, and use of Booleans "and" between mesh terms and "or" among historical findings.

Risk of Bias: According to the Cochrane model for the risk of bias in the present study, the global assessment resulted in 5 studies with a high risk of bias and 6 studies with uncertain risk. In addition, there was an absence of the funding source in 4 studies and 3 studies did not disclose information about the declaration of conflict of interest.

\section{Flow chart}

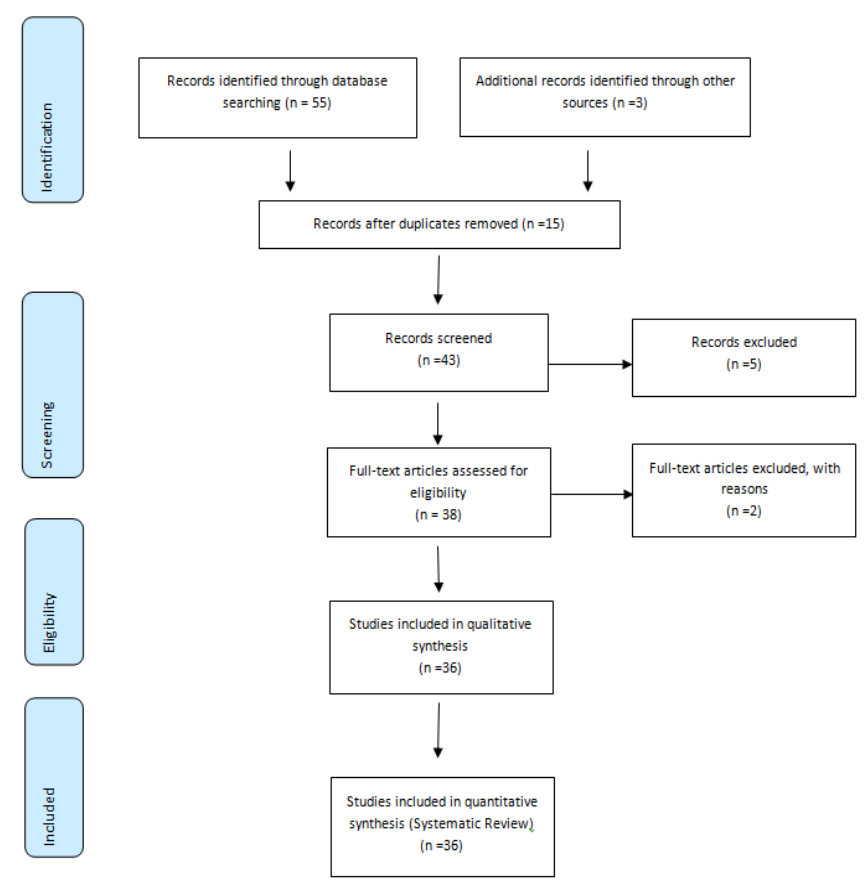

Literature Review - Major Findings: After literary analysis, the treatment of blow-out orbit fractures and the ideal time for the repair of these fractures has been controversial in the literature (28). The advent of computed tomography made it possible to easily define the extent of trauma and the fracture pattern, helping to clarify the need for early treatment. Many patients require surgery, and the early repair (up to two weeks) of these fractures is recommended by several surgeons. However, others believe that the signs/symptoms of some patients improve spontaneously and prefer to wait for 4-6 months before having surgery (Kang, 2019). In this scenario, surgery is recommended for selected patients, including those with extensive fractures of one or more walls of the orbital cavity, involving more than half of its extension, particularly when associated with fracture of the medial wall, evidence of entrapment of orbital tissue, enophthalmos more than $2 \mathrm{~mm}$ in the first two weeks after the trauma, diplopia, and limitation of motility. 
Patients with minimal diplopia or rapid improvement, good eye motility, minimal enophthalmos, and a small extent blowout fracture, without the obvious entrapment of orbital tissues, do not require surgery (Kang, 2019). Early surgery can be selected based mainly on the large extent of the floor fracture and a large amount of herniated tissue into the sinus. After the reduction of the orbital floor fracture, the bone defect can be reconstructed by several alternatives, including autogenous bone, muscle fasciae, and alloplastic materials, such as titanium meshes or poly-p-dyoxanon (PDS) sheets. The objective is to reconstruct the bone defect, restoring the original volume, and restoring the function and aesthetics of the orbital region (Snäll, 2019). In this sense, the convenience, the stability, the lack of morbidity of the donor site, the reduction of anesthetic and operation time convinced many surgeons to use alloplastic materials for the reconstruction of blow-out fractures, among them the titanium mesh. Among the reasons for the preference in using titanium, screens are thin materials, easy to contour, easily stabilized, maintain their shape, and have the ability to compensate for the volume when properly contoured, without the potential for resorption (Rahbin et al., 2019; Snäll, 2019).

In addition, they can easily cross wide defects promoting rigid support, they are visible radiographically and sterilizable. Titanium has the added advantage of producing less computed tomography artifacts than other metals. The titanium mesh is used routinely for the treatment of orbital fractures and has shown good success when used properly. Transconjunctival access to the orbit seems to be the preferred surgical approach for most fractures of the orbital floor, due to its low rate of complications and excellent cosmetic results. This approach has been known for over 75 years but has become widely used 25 years ago (Snäll, 2019). In addition, a study aimed to implement the orbital volume as an objective assessment method to assess the accuracy of unilateral fixation of the fracture of the Orbitozygomatic complex, comparing the postoperative values with the contralateral normal side and the pre-treated values (El-Mahallawy, 2020). Thus, a retrospective radiographic review of medical records was performed in order to investigate the primary outcome of objective quantification of the accuracy of fracture reduction of the Orbitozygomatic complex using orbital volume analysis. The comparison of the values of the postoperative orbital volume with the preoperative and normal contralateral values was defined as a secondary outcome of the study, together with the percentage of changes in the orbital volume of patients treated with unilateral Orbitozygomatic fracture.

Data reliability was performed using the interclass correlation coefficient and statistical significance was established at the $5 \%$ level. Seventeen records met the inclusion criteria. Although a statistically significant difference was found between the values of preoperative orbital volume on the affected side and on the normal unaffected side $(\mathrm{p}<0.001)$, a statistically insignificant difference was found between the postoperative values and the control side $(p=0.333)$. An average percentage drop of $6.1 \%$. it was reported in the postoperative records when compared to the preoperative ones, with a statistically significant difference $(\mathrm{p}<0.001)$. The study reported high reliability of the inter-observer $(\mathrm{ICC}=0.97)$ and Intra $(\mathrm{ICC}=0.97)$. The analysis of the orbital volume offers a valid modality for the objective assessment of the efficiency of the management of fractures of the orbitozygomatic complex (El-Mahallawy, 2020).
Still, another retrospective study evaluated the clinical outcome of the surgical treatment of isolated small or large orbital fractures of the orbital floor (OFFs) using polyglactin 910 / polydioxanone (Ethisorb $\AA$ ) (32). Covering a period of four years (2010-2013), all records referring to fractures of the middle face with orbit involvement were examined. Isolated fractures of the orbital floor were included, as well as combined injuries of the orbital floor and medial wall that were treated surgically with polyglactin 910 / polydioxanone (Ethisorb $\left.{ }^{\circledR}\right)$. Patients underwent late preoperative, postoperative, and ophthalmological evaluation. The clinical results of small OFFs surgically administered up to $2 \mathrm{~cm}^{2}$ were analyzed statistically and compared with the clinical results in major defects. The final sample included 61 patients (25 women, $36 \mathrm{men})$. Fractures of up to $2 \mathrm{~cm} 2$ were found in 33 patients $(54.1 \%)$, while 28 patients $(45.9 \%)$ suffered OFFs greater than $2 \mathrm{~cm}^{2}$. The clinical results did not differ significantly between the two categories of the sample, and the statistical analysis showed a power of 0.91 to detect a potentially existing difference. At the final examination, 52 patients were free of any clinical symptoms, while minor problems were found in seven subjects and two patients suffered severe impairment.

In conclusion, polyglactin 910/polydioxanone (Ethisorb ${ }^{\circledR}$ ) appears to be a suitable material for the surgical repair of small and large OFFs (Steinmassl et al., 2020). In addition, patients with head trauma (HT) may have concomitant OFFs. Thus, a study aimed to determine the specific findings of $\mathrm{CT}$ and to investigate the diagnostic performance of head HT in the detection of OFFs (33). 3,534 patients with head trauma who underwent simultaneous HT of the head and face during a period of three years were analyzed. Clinical data and specific HT findings of the head between patients with and without OFFs were compared. Thus, 198 patients $(5.6 \%)$ had visible OFFs on HT. On head HT, discontinuity of the orbital floor, gas bubbles trapped between floor fragments, lower extraconal emphysema, and upper hemosinus (MHS) were more commonly observed among patients with OFFs $(p<0.001)$. The absence of MHS had a high negative predictive value (99.7\%) to exclude OFFs. Among the different types of MHS, the pattern showing high attenuation opacity mixed with stained gas had the highest positive predictive value $(69.5 \%)$ for OFFs and was the only independent predictor of OFFs after adjustment for the other HT variables. in all patients with MHS. HT can serve as a first-line screening tool to detect OFFs in patients with head trauma. Therefore, unnecessary facial HT and additional radiation exposure can be reduced (Huang, 2019).

In this context, it is believed that the intraorbital content is affected by edema in the days after a fracture at rupture. This edema can be detected by magnetic resonance imaging (MRI) as for changes in muscle volume, in the cross-sectional area of the muscle, and in the RM parameter 'mean ash value' (MAV) of the orbital fat and extra-ocular muscles (EOM) (Felding et al., 2019). Thus, a study selected 18 patients with a rupture fracture who underwent an MRI within 72 hours after the trauma and again after 10 to 14 days. The measures of EOM and adipose tissue in the fractured orbit were compared with the non-fractured orbit. The measurements showed significantly greater volume, cross-sectional area, and MAV of the EOM closer to the fracture compared to the same muscle in the non-fractured orbit. The volume of the orbital content of the hernia was significantly lower in the second scan than in 
the first. Therefore, based on the first longitudinal magnetic resonance study in patients with rupture fractures, the results indicated post-traumatic edema in the intra-orbital soft tissue that disappears between scans. A watchful waiting period is recommended in the early post-traumatic days in patients without muscle entrapment (Felding et al., 2019). Still, although sheets composed of non-synthesized hydroxyapatite and poly-L-lactic acid (u-HA/PLLA) have several applications, such as in craniomaxillofacial fractures, orthognathic surgery and orthopedic surgery, and have been proven to be safe and effective, no study has reported the use of $\mathrm{u}-\mathrm{HA} / \mathrm{PLLA}$ composite plates for the reconstruction of the orbital wall with long-term follow-up (Tsumiyama et al., 2019). Thus, a study reported preliminary results using the uHA/PLLA composite sheet for orbital wall fractures. The SuperFIXSORB MX plate (u-HA/PLLA composite plate; Takiron, Tokyo, Japan), $30 \times 50 \mathrm{~mm}$ in size and $0.5 \mathrm{~mm}$ thick, was used in all cases of hard reconstruction of the orbital bone defect. Seventy-two (72) patients with acute orbital wall fractures (within two weeks after the injury) treated at Jikei University between January 2014 and August 2016 were included. No postoperative complications were observed, such as infection, postoperative diplopia or enophthalmia, due to the use of the u-HA/PLLA composite sheet.

In pure orbital fractures (orbital fractures only), the meantime of operation was significantly longer with combined fractures of the inferior and medial wall $(201.1 \pm 36.6$ minutes; $\mathrm{n}=11)$ than only in fractures of the inferior wall or the medial wall $(135.0 \pm 54.4$ minutes; $n=51)$ (Mann-Whitney $U$ test, $p$ $<0.001)$. The U-HA/PLLA composite plate is safe and can be used for reconstructing orbital wall fractures (Tsumiyama et al., 2001). Finally, contemporary advances in technology have allowed the transfer of industrial laser fusion technology to surgery, and its use can improve the accuracy of orbital restoration. Thus, a study assessed the accuracy of primary orbital reconstruction using selective laser melting, patientspecific implants. 100 patients with complex orbital fractures were included (Rana et al., 2019). The planned orbital volumes were compared with those achieved and the angles were compared with the unaffected side. The analysis included the postoperative overlap in the planned images (iPlan ${ }^{\circledR} 3.0 .5$, Brainlab). The average orbital volume on the unaffected side was 27.2 (2.8) $\mathrm{ml}$ in men and 25.0 (2.6) $\mathrm{ml}$ in women. Fractures involving the posterior third of the orbital floor and crushed fractures showed a significant orbital increase $(\mathrm{p}=$ 0.026). The average reconstructed orbital volume was 26.9 (2.7) $\mathrm{mL}$ in men and $24.26(2.5) \mathrm{mL}$ in women. Therefore, the three-dimensional analysis of the color mapping showed small deviations when compared to the unaffected side. The results suggest that a high degree of accuracy can be achieved routinely in these complex cases (Rana et al., 2019).

\section{Conclusion}

Orbital injuries are frequently seen in facial trauma and can cause a wide range of functional problems such as enophthalmos and diplopia, as well as aesthetic deformities. The need for surgical treatment of these fractures is quite controversial. Some blow-out orbital fractures do not have sequelae if they are not surgically treated, while others can result in aesthetically unacceptable enophthalmos and/or disabling diplopia. The main issue, therefore, is the identification of those patients who require surgical intervention, the time of surgery, and the surgical technique involved.

Competing interests: The authors declare that they have no competing interests.

Funding: Notapplicable.

\section{REFERENCES}

Nazimi AJ, Rajaran JR, Nordin R. 2019. Subperiosteal Dissection in Orbital Blowout Fracture: Technical Tips Including the Use of Modified Periosteal Elevator. $J$ Craniofac Surg. Oct;30(7):e609-e611. doi: 10.1097/SCS. 0000000000005617.

Oliveira CMCS, Santos JS, Brasileiro BF, Santos TS. 2008. Epidemiologia dos traumatismos buco-maxilofaciais por agressões em Aracaju/SE. Rev Cir Traumatol BucoMaxilo-Fac. 8(3):57-68.

Agudelo-Suárez AA, Duque-Serna FL, RestrepoMolina L, Martínez-Herrera E. 2015. Epidemiología de lasfracturasmaxilofaciales por acidente de tráfico en Medellín (Colombia). GacSanit. 29(S1):30-5).

Affonso PRA, Cavalcanti MA, Groisman S, Gandelman I. Etiologia de trauma e lesões faciais no atendimento préhospitalar no Rio de Janeiro. Rev UNINGÁ. 2010; 23(1).

Obimakinde OS, Ogundipe KO, Rabiu TB, Okoje VN. 2017. Maxillofacial fractures in a budding teaching hospital: a study of pattern of presentation and care. Pan Afr Med J., 26:218.

Afrooz PN, Bykowski MR, James IB, Daniali LN, ClavijoAlvarez JA. 2015. The Epidemiology of Mandibular Fractures in the United States, Part 1: A Review of 13,142 Cases from the US National Trauma Data Bank. J Oral Maxillofac Surg., Dec;73(12):2361-6.

Roccia F, Sotong J , Savoini M, Ramieri G, Zavattero E. 2019. Maxillofacial Injuries Due to Traffic Accidents. $J$ Craniofac Surg., Feb 5.

Schneider D, Kämmerer PW, Schön G, Dinu C, Radloff S, Bschorer R. 2015. Etiology and injury patterns of maxillofacial fractures from the years 2010 to 2013 in Mecklenburg-Western Pomerania, Germany: A retrospective study of 409 patients. J Craniomaxillofac Surg., Dec; 43(10):1948-51.

Sameer Kaura, Paramjot Kaur, RashiBahl, Sumit Bansal, and Prineet Sangha. 2018. Retrospective Study of Facial Fractures. Ann Maxillofac Surg., Jan-Jun; 8(1): 78-82.

Bernardino ÍM, Barbosa KGN, Nóbrega LM, Cavalcante GMS, Ferreira EFE. 2017. d\&\#39;Ávila S. Interpersonal violence, circumstances of aggressions and patterns of maxillofacial injuries in the metropolitan area of Campina Grande, State of Paraíba, Brazil (2008-2011). CienSaude Colet. Sep; 22(9): 3033-3044.

Paes JV, de SáPaes FL, Valiati R, de Oliveira MG, Pagnoncelli RM. 2012. Retrospective study of prevalence of face fractures in southern Brazil. Indian J Dent Res., Jan-Feb; 23(1): 80-6.

Jefferson ViapianaPaes, Franciana Lima de Sá Paes, Renato Valiati, Marília G de Oliveira, Rogério Miranda Pagnoncelli Retrospective study of prevalence of face fractures in southern Brazil. Indian J Dent Res. 2012 JanFeb;23(1):80-6.

Affonso PRA, Cavalcanti MA, Groisman S, Gandelman I. 2010. Etiologia de trauma e lesões faciais no atendimento pré-hospitalar no Rio de Janeiro. Rev UNINGÁ.; 23(1). 
Schneider D, Kämmerer PW, Schön G, Dinu C, Radloff S, Bschorer R. 2015. Etiology and injury patterns of maxillofacial fractures from the years 2010 to 2013 in Mecklenburg-Western Pomerania, Germany: A retrospective study of 409 patients. J Craniomaxillofac Surg., Dec;43(10):1948-51.

Jefferson Viapiana Paes, Franciana Lima de Sá Paes, Renato Valiati, Marília G de Oliveira, 2012. Rogério Miranda Pagnoncelli Retrospective study of prevalence of face fractures in southern Brazil. Indian $J$ Dent Res., JanFeb;23(1):80-6.

Ailane Milard Moreira de Souza, Iel Marciano de Moraes Filho, Jessica de Arêa Leão Silva, Mariane Conceição Paixão, Acza Araújo Soreas de Alcântra, Sandra de Nazaré Costa Monteiro. 2019. Perfil epidemiológico e clínico de pacientes adultos jovens admitidos na sala amarela do centro de trauma do hospital de base do distrito federal.revista de divulgação científica sena airES. V.8, N.

Wang H, Song G, Ren W, Zhou Y, Li C, Ou L, Liu J, Xiang L. 2018. Traumatic Facial Fractures in Children and Adolescents. J Craniofac Surg., Oct;29(7):1809-1812.

Muñante-Cárdenas JL, Olate S, Asprino L, de Albergaria Barbosa JR, de Moraes M, Moreira RW. 2011. Pattern and treatment of facial trauma in pediatric and adolescent patients. J Craniofac Surg., Jul;22(4):1251-5.

Scariot R., de Oliveira IA., Passeri LA., Rebellato NL., Müller PR. Maxillofacial injuries in a group of Brazilian subjects under 18 years of age.

Segundo avl; campos vs; vasconcelosbce. Perfil epidemiológico de pacientesportadores de fraturas faciais. Rev. Ciênc. Méd., Campinas, 14(4): 345-350, jul./ago., 2005.

Caio de Andrade Hage, Thiago Brito Xavier, Diandra Costa Arantes, Maurilio de Souza Zampieri, Liliane Silva do Nascimento. Traumas faciais e morbidade bucal provocada pela violência em Belém, estado do Pará, Brasil.Rev. PanAmaz 2018; 9(1): 41-49.

Brucoli M, Boffano P, Broccardo E, Benech A, Corre P, Bertin H, Pechalova P, Pavlov N, Petrov P, Tamme T, Kopchak A, Hresko A, Shuminsky E, Dediol E, Tarle M, Konstantinovic VS, Petrovic M, Holmes S, Karagozoglu KH, Forouzanfar $\mathrm{T}$ The \& quot; Europe anzygomaticfracture \& quot; research project: The epidemiological results from a multicenter European collaboration. J Craniomaxillofac Surg. 2019 Jan 30. pii: S1010-5182(18)30722-4.

Beaudouin F, der Fünten KA, Tröß T, Reinsberger C, Meyer $\mathrm{T}$ Time Trends of Head Injuries Over Multiple Seasons in Professional Male Football (Soccer). Sports Med Int Open. 2019 Jan 28;3(1):E6-E11

Hojjat H, Svider PF, Lin HS, Folbe AJ, Shkoukani MA, Eloy JA, Zuliani G. 2016. Adding Injury to Insult: A National Analysis of Combat Sport-Related Facial Injury. Ann Otol Rhinol Laryngol. Aug; 125(8):652-9.

Benjamin T, Hills NK, Knott PD, Murr AH, Seth R. 2018. Association Between Conventional Bicycle Helmet Use and Facial Injuries After Bicycle Crashes. JAMA Otolaryngol Head Neck Surg., Dec 13.
Plawecki A, Bobian M, Kandinov A, Svider PF, Folbe AJ, Eloy JA, Carron M. 2017. Recreational Activity and Facial Trauma Among Older Adults. JAMA Facial Plast Surg. Dec 1;19 (6):453-458.

Svider PF, Chen M, Burchhardt D, O\&\#39;Brien PS, Shkoukani MA, Zuliani GF, Folbe AJ. 2016. The Vicious Cycle: Pediatric Facial Trauma from Bicycling. Otolaryngol Head Neck Surg., Feb; 154(2):371-6.

Kang DH. 2019. Orbital wall restoring surgery with primary orbital wall fragments in blowout fracture. Arch Craniofac Surg. Dec;20(6):347-353. doi: 10.7181/acfs.2019.00724. Epub 2019 Dec 20.

Rahbin S, Liakos A, Alinasab B. 2019. Loss of Malar Bags in Lower Eyelid in Orbital Blow Out Fracture Reconstruction Following Pre- or Retro-Septal Transconjunctival Incision. J Craniofac Surg., Dec 31. doi: 10.1097/SCS.0000000000006103.

Snäll J, Narjus-Sterba M, Toivari M, Wilkman T, Thorén H. 2019. Does postoperative orbital volume predict postoperative globe malposition after blow-out fracture reconstruction? A 6-month clinical follow-up study. Oral Maxillofac Surg., Mar;23(1):27-34. doi: 10.1007/s10006019-00748-3. Epub 2019 Feb 12.

El-Mahallawy YA, Al-Mahalawy HA. 2020 Evaluation of orbital volume after orbitozygomatic complex fractures fixation: A radiographical study. J Oral BiolCraniofac Res. Apr-Jun;10(2):66-71. doi: 10.1016/j.jobcr.2020.02.001. Epub 2020 Feb 5.

Steinmassl O, Laimer J, Offermanns V, Wildauer M, Steinmassl PA, Grams AE, Kofler F, Rasse M, Bruckmoser E. 2020. Clinical Outcome Following Surgical Repair of Small Versus Large Orbital Floor Fractures Using Polyglactin 910/Polydioxanone $\left(\right.$ Ethisorb $^{\circledR}$ ). Materials (Basel). Jan 3;13(1). pii: E206. doi: 10.3390/ma13010206.

Huang LK, Tu HF, Jiang LD, Chen YY, Fu CY. 2019. Evaluation of Concomitant Orbital Floor Fractures in Patients with Head Trauma Using Conventional Head CT Scan: A Retrospective Study at a Level II Trauma Center. $J$ Clin Med., Nov 2;8(11). pii: E1852. doi: 10.3390/ jcm8111852.

Felding UA, Damgaard OE, Bloch SL, Darvann TA, Thomsen C, Toft PB, von Buchwald C. 2019. Dynamic soft tissue changes in the orbit after a blowout fracture. Acta Otolaryngol. 2019 Nov;139(11):1024-1029. doi: 10.1080/ 00016489.1657239. Epub 2019 Sep 9.

Tsumiyama S, Umeda G, Ninomiya K, Miyawaki T. 2019. Use of Unsintered Hydroxyapatite and Poly-L-lactic Acid Composite Sheets for Management of Orbital Wall Fracture. J Craniofac Surg., Oct;30(7):2001-2003. doi: 10.1097/SCS.0000000000005734.

Rana M, Holtmann H, Rana M, Kanatas AN, Singh DD, Sproll $\mathrm{CK}^{2}$, Kübler NR, Ipaktchi R, Hufendiek K, Gellrich NC. 2019. Primary orbital reconstruction with selective laser melted core patient-specific implants: overview of 100 patients. Br J Oral Maxillofac Surg. 2019 Oct;57(8):782787. doi: 10.1016/j.bjoms.2019.07.012. Epub Jul 27. 